\title{
SCHUR POWER CONVEXITY OF THE DARÓCZY MEANS
}

\author{
ZHEN-HANG YANG
}

Abstract. In this paper, the Schur convexity is generalized to Schur $f$-convexity, which contains the Schur geometrical convexity, harmonic convexity and so on. When $f: \mathbb{R}_{+} \rightarrow \mathbb{R}$ is defined by $f(x)=\left(x^{m}-1\right) / m$ if $m \neq 0$ and $f(x)=\ln x$ if $m=0$, the necessary and sufficient conditions for $f$-convexity (is called Schur $m$-power convexity) of Daróczy means are given, which improve, generalize and unify Shi et al.'s results.

Mathematics subject classification (2010): 26D15, 26D99, 26B25.

Keywords and phrases: Schur convexity, Schur power convex, Schur power concave, Daróczy means.

\section{REFERENCES}

[1] G. D. Anderson, M. K. Vamanamurthy and M. Vuorinen, Generalized convexity and inequalities, J. Math. Anal. Appl. 335, 2 (2007), 1294-1308.

[2] J. S. Aujla AND F. C. Silva, Weak majorization inequalities and convex functions, Linear Algebra Appl. 369 (2003), 217-233.

[3] P. BuRAI, Comparability of certain homogeneous means, Int. Series Nume. Math. 157 (2008), 229232, Birkh ä user Verlag Basel/Switzerland.

[4] Y.-M. Chu, X.-M. Zhang AND G.-D. WANG, The Schur geometrical convexity of the extended mean values, J. Conv. Anal. 15, 4 (2008), 707-718.

[5] Y. M. CHU AND X. M. ZHANG, Necessary and sufficient conditions such that extended mean values are Schur-convex or Schur-concave, J. Math. Kyoto Univ. 48, 1 (2008), 229-238.

[6] Y. M. CHU AND W. F. XIA, Solution of an open problem for Schur convexity or concavity of the Gini mean values, Sci. China Ser. A 52, 10 (2009), 2099-2106. doi: 10.1007/s11425-009-0116-5.

[7] Y.-M. CHU AND Y.-P. LV, The Schur harmonic convexity of the Hamy symmetric function and its applications, J. Inequal. Appl. Vol. 2009, Art. ID 838529, 10 pages, doi:10.1155/2009/838529; available online at http://downloads.hindawi.com/journals/jia/2009/838529.pdf.

[8] G. M. Constantine, Schur convex functions on the spectra of graphs, Disc. Math. 45, 2-3 (1983), $181-188$

[9] Z. Daróczy and L. Losonczi, Über den Vergleich von Mittelwerten, Publ. Math. Debrecen 17 (1970), 289-297.

[10] A. Forcina AND A. Giovagnoli, Homogeneity indices and Schur-convex functions, Statistica 42, 4 (1982), 529-542.

[11] K.-ZH. GuAn And H. T. ZHU, The generalized Heronian mean and its inequalities, Univ. Beograd, Publ. Elektrotehn. Fak., Ser. Mat. 17 (2006), 60-75.

[12] CH. Gu AND H.-N. SHI, Schur-convexity and Schur-geometric convexity of Lehmer Means, Math. Prac. Theory 39, 12 (2009), 183-188.

[13] G. H. Hardy, J. E. Littlewood And G. Pólya, Some simple inequalities satisfied by convex functions, Messenger Math. 58 (1929), 145-152.

[14] F. K. Hwang, U. G. Rothblum and L. Shepp, Monotone optimal multipartitions using Schur convexity with respect to partial orders, SIAM J. Discrete Math. 6, 4 (1993), 533-547.

[15] F. K. Hwang ANd U. G. Rothblum, Partition-optimization with Schur convex sum objective functions, SIAM J. Discrete Math. 18, 3 (2004), 512-524.

[16] W. Janous, A note on generalized Heronian means, Math. Inequal. Appl. 4, 3 (2001), 369-375.

[17] G. JiA AND J. CAO, A new upper bound of the logarithmic mean, J. Inequal. Pure Appl. Math. 4, 4 (2003), Art. 80. 
[18] D.-M LI, CH. GU AND H.-N. SHI, Schur convexity of the power-type generalization of Heronian mean, Math. Prac. Theory 36, 9 (2006), 387-390. (Chinese)

[19] D.-M. LI AND H.-N. SHI, Schur convexity and Schur-geometrically concavity of generalized exponent mean, J. Math. Inequal. 3, 2 (2009), 217-225.

[20] ZH. Liu, Comparison of some means, J. Math. Res. Exp. 22, 4 (2002), 583-588.

[21] A. W. Marshall AND I. Olkin, Inequalities: Theory of Majorization and Its Applications, New York, Academic Press, 1979.

[22] M. Merkle, Convexity, Schur-convexity and bounds for the gamma function involving the digamma function, Rocky Mountain J. Math. 28, 3 (1998), 1053-1066.

[23] F. QI, J. SÁNDOR AND S. S. DRAGOMIR, Notes on the Schur-convexity of the extended mean values, Taiwanese J. Math. 9, 3 (2005), 411-420.

[24] F. QI, A note on Schur-convexity of extended mean values, Rocky Mountain J. Math. 35, 5 (2005), $1787-1793$.

[25] J. SÁndor, The Schur-convexity of Stolarsky and Gini means, Banach J. Math. Anal. 1, 2 (2007), 212-215.

[26] M. Shaked, J. G. Shanthikumar And Y. L. Tong, Parametric Schur convexity and arrangement monotonicity properties of partial sums, J. Multivariate Anal. 53, 2 (1995), 293-310.

[27] H.-N. SHI, S.-H. WU AND F. QI, An alternative note on the Schur-convexity of the extended mean values, Math. Inequal. Appl. 9, 2 (2006), 219-224.

[28] H.-N. SHI, Schur convexity of generalized Heronian means Iinvolving two parameters, J. Inequal. Appl. 2008 (2008), Art. ID 879273, 9 pages, doi:10.1155/2008/879273.

[29] H.-N. SHI, Y.-M. JIANG AND W.-D. JIANG, Schur-convexity and Schur-geometrically concavity of Gini means, Comp. Math. Appl. 57, 2 (2009), 266-274.

[30] C. STEPNIAK, Stochastic ordering and Schur-convex functions in comparison of linear experiments, Metrika 36, 5 (1989), 291-298.

[31] M. K. VAnamurthy And M. Vuorinen, Inequalities for means, J. Math. Anal. Appl. 183 (1994), $55-166$.

[32] B.-Y. WANG, Foundations of majorization inequalities, Beijing Normal Univ. Press, Beijing, China, 1990. (Chinese)

[33] W.-F. XIA, The Schur harmonic convexity of Lehmer means, Inter. Math. Forum 4, 41 (2009), 20092015.

[34] W.-F. XIA AND Y.-M. CHU, Schur-convexity for a class of symmetric functions and its applications, J. Inequal. Appl. 2009 (2009), Art. ID 493759, 15 pages.

[35] ZH.-H. YANG, Simple discriminances of convexity of homogeneous functions and applications, Gāoděng Shùxué Yánjiū (Study in College Mathematics) 4, 7 (2004), 14-19. (Chinese)

[36] ZH.-H. YANG, On the homogeneous functions with two parameters and its monotonicity, J. Inequal. Pure Appl. Math. 6, 4 (2005), Art. 101; available online at http://jipam.vu.edu.au/images/ 155_05_JIPAM/155_05.pdf.

[37] ZH.-H. YANG, On the log-convexity of two-parameter homogeneous functions, Math. Inequal. Appl. 10, 3 (2007), 499-516.

[38] ZH.-H. YANG, On the monotonicity and log-convexity of a four-parameter homogeneous mean, J. Inequal. Appl. 2008 (2008), Art. ID 149286, 12 pages, doi:10.1155/2008/149286; available online at http://www . hindawi.com/GetArticle. aspx?doi=10.1155/2008/149286.

[39] ZH.-H. YANG, Some monotonictiy results for the ratio of two-parameter symmetric homogeneous functions, Int. J. Math. Math. Sci. 2009 (2009), Art. ID 591382, 12 pages, doi:10.1155/2009/591382; available online at http://www.hindawi.com/journals/ijmms/2009/591382.html.

[40] X.-M. ZHANG, Schur-convex functions and isoperimetric inequalities, Proc. Amer. Math. Soc. 126, 2 (1998), 461-470.

[41] X.-M. Zhang, Geometrically Convex Functions, Hefei, An'hui University Press, 2004. (Chinese)

[42] ZH.-H. Zhang AND Y.-D. WU, The generalized Heron mean and its dual form, Appl. Math. E-Notes 5 (2005), 16-23.

[43] ZH.-H. Zhang AND Y.-D. WU, The properties of the generalized Heron means and its dual form, RGMIA Res. Rep. Coll. 7, 2 (2004), Art. 1. 